\title{
Interpersonal Interactions in the Marital Pair and Mental Health: A Comparative and Correlational Study ${ }^{1}$
}

\author{
Gleiber Couto ${ }^{2}$ \\ Universidade Federal de Goiás, \\ Catalão-GO, Brazil
}

\author{
Luc Vandenberghe \\ Pontifícia Universidade Católica de Goiás, \\ Goiânia-GO, Brazil
}

\author{
Wanessa Marques Tavares \\ Universidade Federal de Goiás, \\ Catalão-GO, Brazil
}

\begin{abstract}
Interpersonal interactions as social processes reflect and influence individuals' mental health. The aim of the study was to verify how marital interactions relate to mental health, and to investigate evidence for the validity of the Checklist for Interpersonal Transactions II (CLOIT-II). Participants were 169 couples from the southeast of the Brazilian state of Goiás, aged between 18 and 55 years $(M=21 ; S D=5.48)$. They responded to a General Health Questionnaire (GHQ) and the CLOIT-II. Participants with low mental health problem scores in the GHQ (asymptomatic participants) tended to occupy interpersonal positions in the range between Deference/Trust and Affective warmth/Friendliness. In the group with high scores (symptomatic participants), interactions were defined by Coldness/Hostility. Mental health problems were positively correlated with mistrust, coldness and hostility and negatively correlated with positions of Affiliation. These results, in addition to supporting the validity of the CLOIT-II, indicate that the study of interpersonal relationships is relevant for the understanding of mental health.
\end{abstract}

Keywords: test validity, mental health, interpersonal relationships, marital relationships

\section{Interações Interpessoais no Par Conjugal e Saúde Mental: Um Estudo Comparativo e Correlacional}

\begin{abstract}
Resumo: Interações interpessoais são a base dos processos sociais. Refletem e influenciam o estado de saúde mental dos indivíduos. O objetivo do estudo foi verificar como interações conjugais se relacionam com saúde mental e investigar evidências de validade para o Checklist de Relações Interpessoais-II (CLOIT-II). Participaram 169 casais do sudeste goiano com idades entre 18 e 55 anos $(M=21 ; D P=5,48)$, respondendo ao Questionário de Saúde Geral (QSG) e ao CLOIT-II. Os participantes com baixos escores para problemas de saúde mental no QSG (participantes assintomáticos) apresentaram mais posições interpessoais entre Deferência/Confiança e Calor afetivo/Amigabilidade. No grupo com altos escores (participantes sintomáticos), as interações foram definidas por Frieza afetiva/Hostilidade. Problemas de saúde mental apresentaram correlações positivas com desconfiança, frieza e hostilidade e correlações negativas principalmente com posições Afiliativas. Estes resultados, além de apoiar a validade do CLOITII, mostram a relevância do estudo de relações interpessoais para a compreensão da saúde mental.
\end{abstract}

Palavras-chave: validade do teste, saúde mental, relações interpessoais, relações conjugais

\section{Interacciones Interpersonales en la Pareja Conyugal y Salud Mental: Un Estudio Comparativo y Correlacional}

\begin{abstract}
Resumen: Interacciones interpersonales son la base de procesos sociales. Reflejan e influyen en el estado de salud mental de los individuos. El objetivo del estudio fue verificar las interacciones maritales y su relación con salud mental e investigar evidencia de la validez para el Checklist de Relaciones Interpersonales-II (CLOIT-II). Participaron 169 parejas del sudeste del estado de Goiás, Brasil, con edades entre 18 y 55 años $(M=21 ; D E=5,48)$, que respondieron al Cuestionario de Salud General (CSG) y al CLOIT-II. Los participantes con puntuaciones bajas para los problemas de salud mental en el CSG mostraron más posiciones interpersonales entre Deferencia/Confianza y Calor afectivo/Amabilidad. En el grupo con puntuaciones altas (participantes sintomáticos), las interacciones fueron definidos por Frialdad afectiva/Hostilidad. Problemas de salud mental mostraron correlaciones positivas con desconfianza, frialdad y hostilidad y correlaciones negativas principalmente con posiciones de afiliación. Estos resultados, además de apoyar la validez del CLOIT-II, muestran la relevancia del estudio de las relaciones interpersonales para comprender la salud mental.
\end{abstract}

Palabras clave: validación de test, salud mental, relaciones interpersonales, relaciones conyugales

\footnotetext{
1 Support: Fundação de Apoio à Pesquisa do Estado de Goiás (FAPEG Edital no. 006/2009, Protocol no. 200910267000410).

${ }^{2}$ Correspondence address:

Gleiber Couto. Programa de Pós-Graduação em Gestão Organizacional da Universidade Federal de Goiás - Regional Catalão. Av. Dr. Lamartine Pinto de Avelar, 1120, Setor Universitário. CEP 75704-900. Catalão-GO, Brazil. E-mail: gleibercouto@yahoo.com.br
}

The couple's relationship is perhaps the most typical example of a connection between two individuals. In the past, marriage was strongly related to the idea of procreation, however, soon began to incorporate religious values that continue to influence contemporary marital experiences. At present, couples experience the challenge of maintaining 
traditional values, in a social context that values individuality and professional development (Scorsolini-Comin \& Santos, 2010). Following the expansion of democracy and the feminist movement, the questioning of conjugal life culminated, in the second half of the twentieth century, in a crisis, perceived as a decrease in marriages, increasing divorce rates and the appearance of new family forms. New interpersonal relationship patterns are considered necessary to maintain a healthy marriage (Féres-Carneiro \& Diniz Neto, 2010).

The quality of the marital relationship is associated with the health and psychological and social well-being of the individuals (Sardinha, Falcone, \& Ferreira, 2009). According to Kilmann and Vendemia (2013), husbands that feel discomfort with proximity are more aggressive and less cooperative and responsible, with more secure couples being happier than insecure couples. Abandonment anxiety can make husbands less aggressive and controlling and wives more dependent and self-critical, and less competitive. Unsatisfactory marital relationships are also associated with increased risk for diagnosis of psychopathology, car accidents, physical illness, suicide and violence, among others (Dessen \& Braz, 2000).

Silva (2008) found that problems of adjustment to married life indicate greater health vulnerability, symptoms linked to depression, anxiety and stress. Fink and Shapiro (2013), Whisman (1999) and Whitton and Whisman (2010) also found a relationship between marital dissatisfaction and both depression and anxiety. Furthermore, marital problems have been strongly linked to differences in personality and interpersonal characteristics (Kilmann \& Vendemia, 2013).

Based on the assumption that marital relationships can be comprehended from interactions between the members of the dyad, it is possible that models constructed to map interpersonal patterns can be applied to this issue. The model proposed by Kiesler (1983) is useful for this purpose. The Interpersonal Circle developed by this author is a comprehensive taxonomy of interpersonal behavior. It consists of 16 interpersonal positions that, together, should represent all possibilities to combine the two fundamental dimensions of interpersonal relationships according to Sullivan's theory (1953): (a) Power: the Submission-Dominance dichotomy, and (b) Affiliation: the Friendliness-Hostility dichotomy. Each sector groups attitudes that are characterized by a certain quality (e.g.: cold, controlling, friendly, etc.). Each position is defined by a certain degree of power with a certain degree of affiliation. And every position groups a "prototypical" class of acts, which means that there is a defining quality that is decisive for the inclusion or exclusion of a certain behavior. For an act to be part of a class, it needs to have similarity with typical examples of this class, characterizing a set of interpersonal arrangements or attitudes.

The work of Kiesler (1983) was influenced by his participation in the historical study of the Kaiser Foundation on effects of psychotherapy, led by LaForge, which he attended as an undergraduate student. It was one of the first major projects intended to clarify how psychotherapy could profoundly transform the patient's personality, and produced, as a byproduct, the Interaction circle, later popularized by the work of Leary (1957). The Interaction circle defines the personality as the totality of the consistent patterns of the transactions that a person has with others. These transactions are the attitudes and their interpersonal consequences. According to Sullivan (1953), individuals turn more frequently to interpersonal strategies that resolved their needs in salient relationships in the past. Thus, these attitudes and their consequences give form and content to their personality.

Mental health is characterized by different sets of strategies used in a relatively flexible and moderate way. Psychopathology is characterized by the rigidity and intensity of the interpersonal strategies. Rigidity: the more pathological the personality, the less variety of interpersonal positions the individual uses. Intensity: psychopathology is characterized by extreme and exaggerated forms of some interpersonal patterns (Sullivan, 1953).

After some decades of research, the circumplex model has shown satisfactory predictive capacity in the assessment of interpersonal characteristics. For example, Slaney, Pincus, Uliaszek and Wang (2006) found high interpersonal profile elevation in individuals with maladaptive perfectionism. Salzer et al. (2008) found interpersonal rigidity in patients with generalized anxiety. Later, Couto, Vandenberghe, and Brito (2012) related hostility with interpersonal stress. Furthermore, Couto, Vandenberghe, Tavares, and Silva (2012) found relationships between interpersonal traits and social skills, while Cain et al. (2012) showed that these traits can influence the course of depression and delay its remission. Grosse Holtforth et al. (2014) found an association between interpersonal problems, depressive symptoms and the quality of the therapeutic alliance in psychotherapy. Interpersonal traits also predict the effect of treatment in patients with obesity problems (Lo Coco, Gullo, Scrima, \& Bruno, 2012). In patients with borderline personality disorder, interpersonal patterns predict interpersonal stress, severity of symptoms and the quality of the therapeutic alliance (Salzer et al., 2013). Clinically relevant differences in antisocial behavior, self-mutilation and suicide attempts were also found to be related to interpersonal profiles (Wright et al., 2013). Thus, the identification of the typical interpersonal positions can contribute to the choice of the best way to approach patients and, consequently, provide greater chances of success in the treatment.

Few data are available regarding how this relates to the marital relationship. Although Kilmann (2012) found that marital stress is associated with a pattern of interaction based on interpersonal characteristics of apathy, hostility and dominance, the triangle between the interpersonal pattern, the quality of the couple's interactions and the mental health needs to be studied in more detail. The aim of this study was to determine how marital interactions are related to mental health and to investigate evidence for the validity of the Checklist for Interpersonal Transactions-II (CLOIT-II). In particular, it was contemplated that correlations between measures of mental health and interpersonal positions assessed by the Brazilian version of the Checklist for Interpersonal Transactions-II (Couto, Vandenberghe, \& Van Hattum, 2011) would reveal a source of evidence for the validity of the Checklist. 


\section{Method}

\section{Participants}

This study included 169 heterosexual couples, with 114 married couples and 55 couples in stable relationships, who participated in a project on interpersonal interactions in loving relationships, aged between 18 and 76 years $(M=$ 34 and $S D=12.31)$. At the time of application, $50 \%(n=$ 169) had Complete High School Education, $29.6 \%(n=100)$ Further Education Course, $13.3 \%(n=45)$ Incomplete High School Education and 5.6\% $(n=19)$ Incomplete Elementary Education II. At the time of the data collection no subject had received psychiatric or psychological treatment, nor been recommended such interventions.

\section{Instruments}

Goldberg General Health Questionnaire (GHQ). This instrument was developed to assess an individual's mental health. The assessment is made based on the estimate that the respondent gives regarding the frequency with which they present observable behavioral indicators that characterize their general state of mental health. It consists of 60 items presented with a 4-point Likert scale, ranging from rather less than usual ( 0 points) to much more than usual (3 points) when the item expresses a symptom, with the score being reversed when the item expresses normal behavior. The items are arranged in one general factor $(\alpha=.93)$ representing the intensity of mental health problems, and five specific factors, these being: Psychic Stress $(\alpha=.89)$; Death Wish $(\alpha=.89)$; Lack of Confidence in the Performance Capacity (self-efficacy) $(\alpha=.89)$; Sleep Disorders $(\alpha=.80)$ and Psychosomatic Disorders $(\alpha=.83)$ (Pasquali, Gouveia, Andriola, Miranda, \& Ramos, 1996).

Checklist for Interpersonal Transactions-II (CLOITII). This inventory was constructed to map the interpersonal behavior of targeted people. The Self-classification form should be completed by the target person and contains 96 items that describe actions that may occur in interactions between people. In the form for couples, all the proposals are initiated with "During activities with my spouse...", which is at the top of each page. Participants are asked to mark the items which match their most frequent behaviors when interacting with their spouse. The proposals are divided into 16 two-dimensional segments labeled by the letters $\mathrm{A}$ through $\mathrm{P}$ and distributed around the circle in a counterclockwise direction. The scales and alpha values indicated in the Brazilian manual are: Dominant (A, $\alpha=$ .72), Competitive ( $\mathrm{B}, \alpha=.70)$, Mistrusting ( $\mathrm{C}, \alpha=.74)$, Cold (D, $\alpha=.67)$, Hostile (E, $\alpha=.62$ ), Detached (F, $\alpha=.71$ ), Inhibited ( $\mathrm{G}, \alpha=.72)$, Unassured ( $\mathrm{H}, \alpha=.68)$, Submissive (I, $\alpha=.70)$, Deferent (J, $\alpha=.66)$, Trusting (K, $\alpha=.64)$, Warm (L, $\alpha=.69$ ), Friendly (M, $\alpha=.69$ ), Sociable (N, $\alpha=.68$ ), Exhibitionistic $(\mathrm{O}, \alpha=.74)$, Assured $(\mathrm{P}, \alpha=.69)$. Each sector contains six proposals that describe relationships in two levels of intensity (moderate and high). The raw score ranges from zero to nine and is obtained by adding one or two points, depending on the proposal selected. The 16 segments can be combined to describe more complex patterns of behavior. For example, by adding pairs of segments the following Octants are formed: PA $(\alpha=.80), \mathrm{BC}(\alpha=.77), \mathrm{DE}(\alpha=.73)$, FG $(\alpha=.79)$, HI $(\alpha=.76)$, JK ( $\alpha=.73)$, LM $(\alpha=.79)$, NO $(\alpha=.76)$. Adding the scales that make up each quarter of the circle gives the Quadrants: Hostile-Dominant (Qdt-HD, $\alpha=.88$ ); Hostile-Submissive (Qdt-HS, $\alpha=.84$ ); FriendlySubmissive (Qdt-FS, $\alpha=.84$ ); Friendly-Dominant (Qdt-FD, $\alpha=.83$ ). Furthermore, separate scores are calculated for the four Hemispheres of the circle: Dominant (Hmp-DOM, $\alpha=$ .89); Submissive (Hmp-SUB, $\alpha=.84$ ); Friendly (Hmp-FRI, $\alpha=.87$ ); Hostile (Hmp-HOS, $\alpha=.88$ ). In addition to these, scores are provided that represent the general vector of the target person in each axis of the circle, vertical Control axis (AXS-Control, $\alpha=.89$ ) and horizontal Affiliation axis (AXSAffiliation, $\alpha=.87$ ), using the trigonometric weight of the scores of a determined protocol (Couto et al., 2011).

\section{Procedure}

Data collection. The collection occurred individually with couples and in small groups in the Psychology office of the community support sector on the university campus, with duration of approximately one hour and thirty minutes. The contacts were made among the participants of the extension project "Clinical Psychology and Marriage Planning", which aimed to provide care focused on marital relationships, from the network of relationships of the participants of the research group, and also in a meeting of couples promoted by religious communities of southeastern Goiás. Following the first contact, the participants were asked to indicate other couples that might care to participate, according to the procedure known as the snowballing. Those invited that agreed to participate responded to the GHQ and then the selfclassification form of the CLOIT-II.

Data analysis. At the end of the application, the descriptive statistics of the responses of the subjects to the GHQ were estimated, followed by those of the CLOIT-II. To achieve the study aims, the total scores of the subjects in the GHQ were used to separate them into two groups. The first, the asymptomatic group, was composed of subjects that presented overall scores of two standard deviations below the sample mean or less. The second, the symptomatic group, was composed of subjects that presented overall scores of at least two standard deviations above the sample mean. Next, the interpersonal positions between the two groups were compared using the one-way ANOVA statistical technique and evaluated for statistically significant differences. The circular statistics and the parameters that compose the structural summary [adjustment index (); displacement (); elevation (e) and amplitude $(a)$ ] were also calculated for the circumplex data (Wright, Pincus, Conroy, \& Hilsenroth, 2009). Finally, a study was conducted regarding the relationship between the two measures estimating the Pearson correlation coefficients (r) between the subscales of the GHQ and the interpersonal relationship profile of the CLOIT-II. Disattenuated correlations were calculated and then the correction for attenuation was 
applied, using the formula (Osborne, 2003), where is the corrected correlation, is the disattenuated correlation between the two variables, is the reliability of the first measure and is the reliability of the second measure. For the application of the correction for attenuation, from the data of this sample, the reliability coefficients for internal consistency were estimated. The alpha of the CLOIT-II was calculated based on the matrix of tetrachoric correlations, using the R statistical software, version 3. 1. 1, more appropriate for scales composed of dichotomous choice items, and Cronbach's alpha, suitable for polytomic response scales (Brown, 2002) for the GHQ.

\section{Ethical Considerations}

This study was approved by the Research Ethics Committee of the Universidade Federal de Goiás (Protocol no. 065/2010).

\section{Results and Discussion}

The participants presented means and percentiles [post percentile (pp)] below the indicator for mental health problems. The general pattern of mental health of the sample was (Female: $M=1.81 ; S D=0.38 ; \mathrm{pp}<55$ ) vs. (Male: $M=1.63 ; S D=0.25$; $\mathrm{pp}>45$ ). The results showed no significant differences in relation to gender. However, the men reported fewer symptoms in all the dimensions when compared to the women.

The next step was to estimate the more frequent interpersonal relationship characteristics in both groups and compare them. The results of this comparison are presented in Figure 1. It can be noted that, the subjects of the symptomatic group used more characteristics associated with the Dominant Hemisphere to describe their interpersonal interactions, while the subjects of the asymptomatic group used the characteristics of the Friendly Hemisphere more intensively.

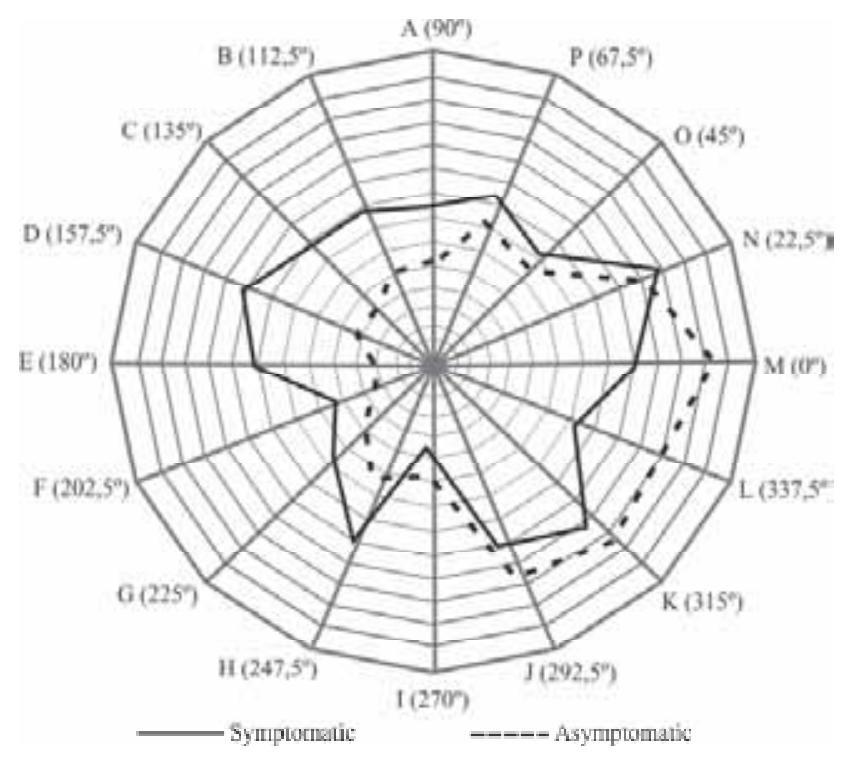

Figure 1. Comparison of interpersonal positions between the groups. $\mathrm{A}=$ Dominant, $\mathrm{B}=$ Competitive, $\mathrm{C}=$ Mistrusting, $\mathrm{D}=$ Cold, $\mathrm{E}=$ Hostilite, $\mathrm{F}=$ Detached, $\mathrm{G}=$ Inhibited, $\mathrm{H}=$ Unassured, $\mathrm{I}=$ Submissive, $\mathrm{J}=$ Deferent, $\mathrm{K}=$ Trusting, $\mathrm{L}=$ Warm, $\mathrm{M}=$ Friendly, $\mathrm{N}$ $=$ Sociable, $\mathrm{O}=$ Exhibitionistic, $\mathrm{P}=$ Assured.
When comparing the interpersonal profiles of the two groups, as seen in Figure 1, the asymptomatic group showed higher means in the scales of the Friendly-Submissive Quadrant, with significant differences in the Friendly $[F(1,30)=2.04 ; p<.05]$ and $\operatorname{Warm}[F(1,30)=2.18 ; p<$ $.04]$ scales. These results indicate that people who do not present mental health problems generally tend to assume warmer and friendlier interpersonal positions with their partners, characterized by a degree of passivity, compared with people who present more complaints related to their mental health. They feel comfortable in the company of their partners, express their positive affection openly, demonstrate involvement and willingness to help, are not reluctant to place their partners ahead of themselves and are not bothered by doing things their way. Conversely, the symptomatic group presented higher means in the scales of the Hostile Hemisphere, specifically in the Hostile-Dominant quadrant, with a marginal difference found for Competitive $[F(1,31)=$ -1.94; $p<.06]$, while for the Mistrusting $[F(1,31)=-2.41$; $p<.02]$, Cold $[F(1,31)=-3.61 ; p<.01]$ and Hostile $[F(1$, $31)=-3.69 ; p<.01]$ scales the differences were significant. These results, especially in relation to hostility, are consistent with those found by Kilmann (2012), and also reinforce the interpretation that mental health characterizes people who more frequently assume interpersonal positions with their partners based on trust, who demonstrate interest in contact and readiness to help, display fewer disputes for attention or centralization of affection, calmly talk about their lives, do not feel cornered or pressured into rules of conduct and are less pessimistic than people who's mental health is disturbed or compromised. These results are similar to those found by Silva (2008).

Table 1 presents the means and the results of the oneway ANOVA, comparing the groups in the derived scales. As can be verified, when the Axis, Hemispheres and Quadrants are examined, the general pattern of the responses shows that the participants of the asymptomatic group avoid positions in which they have to exercise control over their partners, or in which the exercise of their influence is necessary, manipulative and combative attitudes, most frequently assuming complacent positions, considering their partners' perspectives, when compared to the participants of the symptomatic group.

The two groups differed in characteristics related to hostility, which is distinguished by interpersonal positions that make contact with other people exhausting and costly, even when considering passive hostility, more linked to attitudes of isolation, insecurity and inadequacy of beliefs, confirming the results of Couto, Vandenberghe, Tavares et al. (2012) and associated with social inability. When considering active hostility, linked to attitudes of competition, distrust and disregard in contact with other people, this is even more intense. Such hostility characteristics, both active and passive, according to the results of Couto, Vandenberghe and Brito (2012), are related to stress. Similarly, according to Whisman (1999), anxiety and depression characteristics are also linked to marital dissatisfaction. Therefore, it can be speculated that the characteristics present in this group refer to the relationship 
Table 1

Means (Standard Deviations) and ANOVA Between the Groups in the Derivative Scales

\begin{tabular}{|c|c|c|c|c|}
\hline & Symptomatic & Asymptomatic & $\mathrm{F}$ & $p$ \\
\hline Control-Axis & $2.31(10.59)$ & $-4.82(5.99)$ & -2.27 & $.03 *$ \\
\hline Affiliation-Axis & $4.84(12.24)$ & $17.29(8.26)$ & 3.26 & $.00 *$ \\
\hline Hmp-DOM & $20.14(7.41)$ & $13.72(7.47)$ & -2.36 & $.03 *$ \\
\hline Hmp-FRI & $22.78(7.73)$ & $26.26(10.13)$ & 1.06 & .30 \\
\hline Hmp-SUB & $17.83(5.36)$ & $18.54(7.74)$ & 0.29 & .77 \\
\hline Hmp-HOS & $17.94(8.25)$ & 8.97 (5.88) & -3.43 & $.00 *$ \\
\hline Qdt-FD & $18.56(5.20)$ & $17.40(7.69)$ & -0.48 & .63 \\
\hline Qdt-FS & $17.21(6.72)$ & 22.28 (7.69) & 1.92 & .06 \\
\hline Qdt-HS & $12.92(6.09)$ & $8.92(5.55)$ & -1.88 & .07 \\
\hline Qdt-HD & $16.80(7.71)$ & $7.97(6.19)$ & -3.46 & $.00 *$ \\
\hline
\end{tabular}

Note. Hmp-DOM = Dominant hemisphere; Hmp-FRI = friendly hemisphere; Hmp-SUB = submissive hemisphere; Hmf-HOS = hostilite hemisphere; Qdt-FD = friendly-dominant quadrant; Qdt-FS = friendly-submissive quadrant; Qdt-HS = hostile-submissive quadrant; Qdt-HD $=$ hostile-dominant quadrant.

$* p<.05$.

problems with their partners. Furthermore, the two groups differed in passive "friendliness", distinguished by positions linked to displays of affection and willingness to help in interpersonal contact, which are also associated with a broader social skills repertoire, according to Couto, Vandenberghe, Tavares and Silva (2012). These results suggest a two-way route relating the impairment of mental health to difficulties in healthy interaction. The greater the impairment of mental health, the more frequent the appearance of rigid interpersonal positions, or vice versa.

When observing the differences of the two groups in the various characteristics of interpersonal positions, it can be asked, what would be the typical actions of the subjects in each group? The most accurate way to provide an answer to this question, according to Wright et al. (2009), is to use the method of structural summery for circumplex data. Therefore, the structural summary parameters were calculated, checking the position of each subject within the circle to formulate an estimate of the interpersonal position assumed by the group from the individual estimates of these relationships. Also, in order to refine this interpretation and verify possible overlaps between interpersonal positions of the individuals in the groups, the circular statistics and other parameters of the structural summary were calculated, which are presented in Table 2.

The results showed that, when analyzing the value of $R^{2}$, the two groups presented "interpersonal prototypicality", especially evident for the symptomatic group. Such prototypicality, according to Wright et al. (2009), refers to the fact that the group can be described as conforming to a specific interpersonal theme and is reinforced by the amplitude coefficient, since the two measures presented correlations close to .70 . In the case of the results observed by the angular displacement, it should be noted that for the asymptomatic group the peak of the curve can be located in the border position between Deferent-Trusting [JK] and Warm-Friendly [LM], while for the symptomatic group the peak was in the Cold-Hostile [DE] scale. The last two
Table 2

Comparison of Interpersonal Positions Between the Groups

\begin{tabular}{lcc}
\hline & Asymptomatic & Symptomatic \\
\hline Structural Summary & & \\
$\mathrm{R}^{2}$ & 0.76 & 0.87 \\
Displacement & $329.73^{\circ}$ & $167.48^{\circ}$ \\
Elevation & -0.9 & 0.23 \\
Amplitude & 0.30 & 0.66 \\
Circular Statistics & & \\
M & $316.98^{\circ}$ & $183.47^{\circ}$ \\
Variance & $66.04^{\circ}$ & $60.53^{\circ}$ \\
$95 \%$ CI & $283.55^{\circ}-350.40^{\circ}$ & $152.85^{\circ}-214.11^{\circ}$ \\
\hline
\end{tabular}

scales represent diametrically opposed points on the circle, allowing the interpretation that the better the mental health of the subjects, the more displays of affection and friendship are expressed in relationships with their partners, with the opposite also being true. The symptomatic group was found to be more strongly characterized by the use of interpersonal positions of coldness and hostility. When the elevation is analyzed, the values show the presence of more interpersonal stress in this group.

Furthermore, the circular statistics show that there is no overlap of subjects in the two groups. The mean of the angular positions places the symptomatic group in the position of coldness and hostility, as seen in other indicators, and the confidence intervals show that there are subjects in this group that can be characterized as assuming positions from distrust and competition up to isolation and inhibition (data of Table 2 in Figure 1). On the contrary, the asymptomatic group is characterized by interpersonal positions between trusting and warm, which are balanced in JK. When the confidence intervals are observed, it can be said that a variety of interpersonal positions exist in the asymptomatic group 
extending over the entire Friendly-Submissive quadrant. Thus, although there is prototypicality in both groups and they can be described based on interpersonal themes that are specific and distinct from each other, it can be considered that there is greater interpersonal diversity in the asymptomatic group than in the symptomatic group. This finding extends the theoretical propositions about psychopathology suggested by the model by Leary (1957) and previously by Sullivan (1953) to the realm of marital problems.

The next step was to calculate the Pearson correlation coefficients for the types of mental health problems and interpersonal marital positions. This was followed by the values of internal consistency for the precision indices being estimated for the general score and for each subscale of the two tests. Finally, the correlation value was calculated after applying the attenuation correction. The results for the main and derived scales are presented in Table 3, with the reliability index value in parentheses next to the name of each variable or scale. In the columns the disattenuated correlation coefficients are presented in parentheses, with the correlation indexes after attenuation correction shown outside the parentheses.

Significant correlations, after correction ranged between $r=-.38$ and $r=.45$ for the derived scales and between $r=$ $-.23, r=.41$ for the main scales (Table 3 ). When the derived scales were examined, it was found that significant and positive correlations of moderate intensity were more frequent with the scales of the Hostile Hemisphere, specifically of the HostileDominant Quadrant, while significant and negative correlations were more frequent among the scales of the FriendlySubmissive Quadrant. Significant negative correlations were more prominent with the Affiliation Axis, demonstrating that the more interpersonal positions based on friendly contact with the partner, the better the mental health (Table 3).

This result suggests that the more frequent hostile interpersonal positions (more specifically, hostile and domineering), the lower the overall mental health (especially tension experiences, irritation, overload and hopelessness about the future, but also lack of confidence in one's capacity, insomnia and complaints of weakness, pains and chills). On the one hand, the more dominance characteristics outweigh submission characteristics (especially hostile dominance), the worse the symptoms of stress and the lower the allocation of value to the individual's own life. On the other hand, the more friendly characteristics outweigh hostile characteristics, the fewer complaints of stress and psychosomatic problems, the better the outlook on life and greater the belief in the individual's own ability.

In general the coefficients tended to be highest among interpersonal positions which characterize certain interaction difficulties. For example, the Mistrusting, Cold and Hostile scales presented moderate positive correlation with the General Mental Health problems indicator and especially with the Psychic Stress scale, the relationship with the other mental health problem indicators was present, however less intense (Table 3). The Detached, Inhibited and Unassured scales significantly correlated with General Mental Health and with almost all the specific indicators. In particular, a moderate correlation was observed between the Detached scale and the Psychic Stress and Death Wish indicators, and between the Inhibited scale and Psychosomatic Disorders. Thus, in a two-way direction, people who feel useless or experience life as a constant, exhausting and miserable struggle, tend to present evasive interpersonal positions, expect negative intentions from the partners, are insensitive, hostile and rigid, or, on the contrary, the negative interpersonal positions lead to an unhappy life experience.

These results are consistent with those found by Couto, Vandenberghe, and Brito (2012), which showed the relationship between interpersonal positions of this type and stress, and are also similar to the results of Couto, Vandenberghe, Tavares et al. (2012), which showed a relationship between these positions and low social skills. Conversely, the Deferent and Trusting scales showed significant negative correlations with Psychic Stress and Death Wish, respectively, while the Warm scale showed significant negative correlations with all the indicators of problems, except for Sleep Disorders; and the Friendly scale showed significant negative correlations with General Mental Health, Psychic Stress and Death Wish. This result reinforces the interpretation proposed, showing that interpersonal positions based on consideration for the partner, trust, warmth, demonstrations of affection and understanding are more common in people who complain less and have a more positive perspective regarding life.

In an attempt to explain this result, it was noted that, firstly, socially appropriate interactions necessarily require a certain degree of willingness for interpersonal contact. Secondly, a broader set of mental health problems, in addition to all the subjective discomfort caused for the individual, also impact directly on the ability of these people to develop more positive interaction patterns. Therefore, feelings of overload, tension and irritability, beliefs of inability to solve problems, psychosomatic complaints and also a pessimistic perspective regarding the future, give the subject a more intense and less qualified level of interpersonal activity. This was seen in the difference in the value of the elevation coefficient and the intensity of the scores of the scales of the dominant hemisphere, especially the hostile dominant quadrant, when compared to the group of subjects experiencing few or none of these problems. On the contrary, people that present a more positive life experience, without the experience of discomfort and subjective suffering, show less internal pressure for interpersonal contact and present lower intensity of activity and better skills in the interactions, more frequently adopting interpersonal positions based on warm, friendly and confident contact with their partners.

The aim of this study was to determine how marital interactions are related to mental health and to investigate evidence for the validity of the Checklist for Interpersonal Transactions-II (CLOIT-II). When analyzing the results, it was observed that the interpersonal positions of the participants assumed with their respective partners vary according to their mental health profile, demonstrating that healthier people present more suitable interaction patterns. For example, in the asymptomatic group a greater presence 
Table 3

Reliability and Attenuated Correlations (Disattenuated) Between Interpersonal Interactions and General Health

\begin{tabular}{|c|c|c|c|c|c|c|}
\hline & $\begin{array}{c}\text { General Mental } \\
\text { Health } \\
(\alpha=.93)\end{array}$ & $\begin{array}{c}\text { Stress } \\
(\alpha=.87)\end{array}$ & $\begin{array}{l}\text { Death wish } \\
\qquad(\alpha=.87)\end{array}$ & $\begin{array}{l}\text { Self-efficacy } \\
\qquad(\alpha=.85)\end{array}$ & $\begin{array}{c}\text { Sleep } \\
\text { disorders } \\
(\alpha=.79) \\
\end{array}$ & $\begin{array}{c}\text { Psychosomatic } \\
\text { disorders } \\
(\alpha=.78)\end{array}$ \\
\hline $\mathrm{A}(\alpha=.76)$ & $.20(.17)^{* *}$ & $.26(.21)^{* *}$ & .10 & .11 & .10 & .12 \\
\hline $\mathrm{B}(\alpha=.71)$ & $.22(.18)^{* *}$ & $\mathbf{. 3 0}(.24)^{* *}$ & $.20(.16)^{* *}$ & $.18(.14)^{*}$ & .05 & .11 \\
\hline $\mathrm{C}(\alpha=.77)$ & $\mathbf{. 3 8}(.32)^{* *}$ & $\mathbf{. 4 1}(.33)^{* *}$ & $\mathbf{. 3 8}(.31)^{* * *}$ & $.29(.23)^{* *}$ & $.23(.18)^{* * *}$ & $.26(.20)^{* *}$ \\
\hline $\mathrm{D}(\alpha=.65)$ & $.35(.27)^{* *}$ & $.36(.27)^{* *}$ & $.31(.23)^{* *}$ & $.24(.18)^{* *}$ & $.28(.20)^{* *}$ & $.34(.24)^{* *}$ \\
\hline $\mathrm{E}(\alpha=.74)$ &. $\mathbf{3 8}(.31)^{* *}$ &. $\mathbf{4 0}(.32)^{* *}$ & $.34(.27)^{* *}$ & $.33(.26)^{* *}$ & $.16(.12)^{*}$ & $.24(.18)^{* *}$ \\
\hline $\mathrm{F}(\alpha=.72)$ & $.20(.16)^{* *}$ & $.22(.17)^{* *}$ & $.18(.14)^{*}$ & .08 & .07 & .09 \\
\hline $\mathrm{G}(\alpha=.55)$ & $.25(.18)^{* *}$ & $.23(.16)^{* *}$ & .10 & .09 & .10 & $\mathbf{. 3 2}(.21)^{* *}$ \\
\hline $\mathrm{H}(\alpha=.44)$ & $.25(.16)^{* *}$ & $\mathbf{3 1}(.19)^{* * *}$ & $\mathbf{. 3 0}(.18)^{* *}$ & $.25(.15)^{*}$ & .06 & .04 \\
\hline $\mathrm{I}(\alpha=.64)$ & -.00 & .00 & .02 & -.07 & .05 & -.07 \\
\hline $\mathrm{J}(\alpha=.55)$ & -.10 & $-.19(-.13)^{*}$ & -.11 & -.07 & -.06 & -.03 \\
\hline $\mathrm{K}(\alpha=.70)$ & -.08 & -.07 & $-.23(-.18)^{* *}$ & -.03 & -.02 & -.05 \\
\hline $\mathrm{L}(\alpha=.66)$ & $-.22(-.17)^{* *}$ & $-.21(-.16)^{*}$ & $-.22(-.17)^{* * *}$ & $-.23(-.17)^{* *}$ & -.04 & $-.18(-.13)^{*}$ \\
\hline $\mathrm{M}(\alpha=.75)$ & $-.14(-.12)^{*}$ & $-.18(-.15)^{*}$ & $-.18(-.15)^{*}$ & -.08 & .02 & -.09 \\
\hline $\mathrm{N}(\alpha=.71)$ & -.01 & .01 & -.10 & .03 & .01 & -.02 \\
\hline $\mathrm{O}(\alpha=.67)$ & $.23(.19)^{* *}$ & $.29(.23)^{* *}$ & $.22(.17)^{* *}$ & $.15(.12)^{*}$ & $.17(.13)^{*}$ & $.23(.17)^{* *}$ \\
\hline $\mathrm{P}(\alpha=.51)$ & .10 & .12 & .01 & .08 & $.20(.13)^{*}$ & .05 \\
\hline Qdt-HD $(\alpha=.91)$ & $.39(.34)^{* *}$ &. $\mathbf{4 3}(.37)^{* *}$ &. $\mathbf{3 4}(.29)^{* *}$ & $.29(.25)^{* *}$ & $.22(.18)^{* *}$ & $.28(.23)^{* *}$ \\
\hline Qdt-HS $(\alpha=.86)$ & $\mathbf{. 3 0}(.25)^{* *}$ & $\mathbf{. 3 1}(.25)^{* *}$ & $.26(.21)^{* *}$ & $.20(.16)^{*}$ & $.16(.12)^{*}$ & $.20(.15)^{*}$ \\
\hline Qdt-FS $(\alpha=.87)$ & $-.16(-.14)^{*}$ & $-.18(-.15)^{*}$ & $-.22(-.18)^{* *}$ & -.12 & -.03 & -.11 \\
\hline Qdt-FD $(\alpha=.84)$ & .11 & $.17(.14)^{*}$ & .01 & .09 & $.17(.13)^{*}$ & .08 \\
\hline Hmp-DOM $(\alpha=.90)$ & $.30(.26)^{* *}$ & $\mathbf{. 3 6}(.31)^{* *}$ & $.22(.19)^{* *}$ & $.23(.19)^{* *}$ & $.21(.17)^{* *}$ & $.23(.18)^{* *}$ \\
\hline Hmp-SUB $(\alpha=.83)$ & .02 & .03 & -.01 & -.01 & .03 & .00 \\
\hline Hmp-FRI $(\alpha=.83)$ & -.07 & -.06 & $-.17(-.14)^{*}$ & -.04 & .02 & -.04 \\
\hline Hmp-HOS $(\alpha=.91)$ & $.41(.36)^{* *}$ & $.45(.38)^{* *}$ & $.37(.31)^{* *}$ & $.31(.26)^{* *}$ & $.24(.19)^{* *}$ &. $\mathbf{3 3}(.26)^{* *}$ \\
\hline AXS-Cont. $(\alpha=.90)$ & $.26(.23)^{* *}$ & $.32(.27)^{* *}$ & $.22(.19)^{* *}$ & $.23(.19)^{* *}$ & $.17(.14)^{* *}$ & $.21(.17)^{* *}$ \\
\hline AXS-Afil. $(\alpha=.83)$ & $-.37(-.32)^{* *}$ & $-.38(-.32)^{* *}$ & $-.40(-.34)^{* *}$ & $-.27(-, 22)^{* *}$ & $-.15(-, 12)^{* *}$ & $-.28(.22)^{* *}$ \\
\hline
\end{tabular}

Note. The bold values highlight the moderate correlations.

$* p<.05 . * * p .01$.

was noted of interpersonal patterns and friendly attitudes, such as the demonstration of tenderness, affection and willingness to help, as well as interest in the well-being of the people with whom they interact. In the group with more compromised mental health, the people more frequently presented cold and hostile interpersonal positions.

In particular, the results can be considered a source of evidence for the validity of the CLOIT-II, as the interpersonal variables measured by it were found to be related to variables that they should theoretically be related to. As expected, negative interpersonal interaction patterns presented positive correlations with mental health impairment indicators, and positive interpersonal positions presented negative correlations with these indicators. Furthermore, our comprehension of interpersonal dynamics is strengthened by the observation that the negative correlations are stronger than the positive ones, as previously discussed.

An important consideration is the fact that the sample combined people who sought help in a program of assessment and guidance regarding interpersonal behavior in marital relations and participants who did not seek help, however, accepted an invitation by the researchers. It is believed that the group that sought help suffered less influence of social desirability, a commonly recognized element in the results of self-report instruments. Taking into account the diversity of the sample, the results can be considered to be a reasonable descriptions of the phenomena studied. Further studies are suggested that attempt to replicate these results and also that use different methods to improve the observations regarding the psychological dimensions studied. 


\section{References}

Brown, J. D. (2002). Statistics corner: Questions and answers about language testing statistics: The Cronbach alpha reliability estimate. Shiken: JALT Testing\& Evaluation SIG Newsletter, 6(1), 17-19. Retrieved from www:// http://jalt.org/test/bro_13.htm

Cain, N. M., Ansell, E. B., Wright, A. G. C., Hopwood, C. J., Thomas, K. M., Pinto, A., . . . Grilo, C. M. (2012). Interpersonal pathoplasticity in the course of major depression. Journal of Consulting and Clinical Psychology, 80(1), 78-86. doi:10.1037/a0026433

Couto, G., Vandenberghe, L. M. A., \& Van Hattum, A. C. (2011). Manual para o Checklist de Relações Interpessoais - II: Manual técnico [Manual for the Checklist of Interpersonal Transactions - II: Technical manual]. Catalão, GO: Universidade Federal de Goiás.

Couto, G., Vandenberghe, L., \& Brito, E. A. G. (2012). Interações interpessoais e estresse entre policiais militares: Um estudo correlacional [Interpersonal transactions and stress among military Police officers: A correlational study]. Arquivos Brasileiros de Psicologia, 64(2), 47-63.

Couto, G., Vandenberghe, L., Tavares, W. M., \& Silva, R. L. F. C. (2012). Interações e habilidades sociais entre universitários: Um estudo correlacional [Transactions and social skills among university students: A correlation study]. Estudos de Psicologia (Campinas), 29(Supl. 1), 667-677. doi:10.1590/S0103-166X2012000500003

Dessen, M. A., \& Braz, M. P. (2000). Rede social de apoio durante transições familiares decorrentes do nascimento de filhos [Social support network during family transitions to parenthood]. Psicologia: Teoria e Pesquisa, 16(3), 221-231. doi:10.1590/S0102-37722000000300005

Féres-Carneiro, T., \& Diniz Neto, O. (2010). Construção e dissolução da conjugalidade: Padrões relacionais [Relational patterns of the construction and dissolution of conjugality]. Paidéia (Ribeirão Preto), 20(46), 269-278. doi:10.1590/S0103-863X2010000200014

Fink, B. C., \& Shapiro, A. F. (2013). Coping mediates the association between marital instability and depression, but not marital satisfaction and depression. Couple and Family Psychology: Research and Practice, 2(1), 1-13. doi: $10.1037 / \mathrm{a} 0031763$

Grosse Holtforth, M., Altenstein, D., Krieger, T., Flückiger, C., Wright, A. G. C., \& Caspar, F. (2014). Interpersonal differentiation within depression diagnosis: Relating interpersonal subgroups to symptom load and the quality of the early therapeutic alliance. Psychotherapy Research, 24(4), 429-441. doi:10.1080/10503307.2013.829253

Kiesler, D. J. (1983). The 1982 interpersonal circle: A taxonomy for complementarity in human transactions. Psychological Review, 90(3), 185-214. doi:10.1037/0033295X.90.3.185

Kilmann, P. R. (2012). Personality and interpersonal characteristics within distressed marriages. The Family
Journal, 20(2), 131-139. doi:10.1177/1066480712439532

Kilmann, P. R., \& Vendemia, J. M. C. (2013). Partner discrepancies in distressed marriages. The Journal of Social Psychology, 153(2), 196-211. doi:10.1080/00224 545.2012 .719941

Leary, T. (1957). Interpersonal diagnosis of personality: A functional theory and methodology for personality evaluation. New York, NY: Ronald Press.

Lo Coco, G., Gullo, S., Scrima, F., \& Bruno, V. (2012). Obesity and interpersonal problems: Analysis with the interpersonal circumplex. Clinical Psychology \& Psychotherapy, 19(5), 390-398. doi:10.1002/cpp.753

Osborne, J. W. (2003). Effect sizes and the disattenuation of correlation and regression coefficients: Lessons from educational psychology. Practical Assessment, Research \& Evaluation, 8(11), 1-5.

Pasquali, L., Gouveia, V. V., Andriola, W. B., Miranda, F. J., \& Ramos, A. L. M. (1996). Questionário de Saúde Geral de Goldberg: Manual técnico [Goldberg's General Health Questionnaire: Technical manual]. São Paulo, SP: Casa do Psicólogo.

Salzer, S., Pincus, A. L., Hoyer, J., Kreische, R., Leichsenring, F., \& Leibing, E. (2008). Interpersonal subtypes within generalized anxiety disorder. Journal of Personality Assessment, 90(3), 292-299. doi:10.1080/00223890701885076

Salzer, S., Streeck, U., Jaeger, U., Masuhr, O., Warwas, J., Leichsenring, F., \& Leibing, E. (2013). Patterns of interpersonal problems in borderline personality disorder. Journal of Nervous and Mental Disease, 201(2), 94-98. doi:10.1097/NMD.0b013e3182532b59

Sardinha, A., Falcone, E. M. O., \& Ferreira, M. C. (2009). As relações entre a satisfação conjugal e as habilidades sociais percebidas no cônjuge [The relations between marital satisfaction and social skills perceived in the spouse]. Psicologia: Teoria e Pesquisa, 25(3), 395-402. doi:10.1590/S0102-37722009000300013

Silva, M. A. (2008). Trabalho, relacionamento marital e saúde (Doctoral dissertation,. Pontifícia Universidade Católica do Rio Grande do Sul, Porto Alegre, Brazil). Retrieved from http://repositorio.pucrs. br/dspace/bitstream/10923/4819/1/000403090Texto\%2BCompleto-0.pdf

Scorsolini-Comin, F., \& Santos, M. A. (2010). Satisfação conjugal: Revisão integrativa da literatura científica nacional [Marital satisfaction: Integrative review of national scientific literature]. Psicologia: Teoria e Pesquisa, 26(3), 525-531. doi:10.1590/S010237722010000300015

Slaney, R. B., Pincus, A. L., Uliaszek, A. A., \& Wang, K. T. (2006). Conceptions of perfectionism and interpersonal problems: Evaluating groups using the structural summary method for circumplex data. Assessment, 13(2), 138-153. doi:10.1177/1073191105284878

Sullivan, H. S. (1953). The interpersonal theory of psychiatry. New York, NY: Norton. 
Whisman, M. A. (1999). Marital dissatisfaction and psychiatric disorders: Results from the national comorbidity survey. Journal of Abnormal Psychology, 108(4), 701-706. doi:10.1037/0021-843X.108.4.701

Whitton, S. W., \& Whisman, M. A. (2010). Relationship satisfaction instability and depression. Journal of Family Psychology, 24(6), 791-794. doi:10.1037/a0021734

Wright, A. G. C., Pincus, A. L., Conroy, D. E., \& Hilsenroth, M. J. (2009). Integrating methods to optimize circumplex description and comparison of groups. Journal of Personality Assessment, 91(4), 311-322. doi:10.1080/00223890902935696

Wright, A. G. C., Hallquist, M. N., Morse, J. Q., Scott, L. N., Stepp, S. D., Nolf, K. A., \& Pilkonis, P. A. (2013). Clarifying interpersonal heterogeneity in borderline personality disorder using latent mixture modeling. Journal of Personality Disorders, 27(2), 125-143. doi:10.1521/pedi.2013.27.2.125

Gleiber Couto is an Associate Professor of the Universidade Federal de Goiás.

Luc Vandenberghe is a Professor of the Pontifícia Universidade Católica de Goiás.

Wanessa Marques Tavares is a M.S. candidate in Organizational Management of the Universidade Federal de Goiás.

Received: Oct. 27, 2014

1st Revision: Apr. 1, 2015

Approved: Apr. 13, 2015

How to cite this article:

Couto, G., Vandenberghe, L., \& Tavares, W. M. (2015). Interpersonal interactions in the marital pair and mental health: A comparative and correlational study. Paidéia (Ribeirão Preto), 25(62), 373-381. doi:10.1590/198243272562201511 